\title{
$\frac{12}{6} / \lambda^{-95}$ y $\delta(1)$
}

UCRL-ID-120159

\section{Core, Edge, and Divertor LIDAR Thomson Scattering for ITER}

\author{
A.W. Molvik, E.B. Hooper, R.A. Lerche, M.D. Perry
}

April 26, 1995

This is an informal report intended primarily for internal or limited external. distribution. The opinions and conclusions stated are those of the authorand may or may not be those of the Laboratory.

Work performed under the auspices of the U.S. Department of Energy by the Lawrence Livermore National Laboratory under Contract W-7405-Eng-48. 


\section{DISCLAIMER}

This report was prepared as an account of work sponsored by an agency of the United States Government. Neither the United States Government nor any agency thereof, nor any of their employees, make any warranty, express or implied, or assumes any legal liability or responsibility for the accuracy, completeness, or usefulness of any information, apparatus, product, or process disclosed, or represents that its use would not infringe privately owned rights. Reference herein to any specific commercial product, process, or service by trade name, trademark, manufacturer, or otherwise does not necessarily constitute or imply its endorsement, recommendation, or favoring by the United States Government or any agency thereof. The views and opinions of authors expressed herein do not necessarily state or reflect those of the United States Government or any agency thereof. 


\section{DISCLAIMER}

Portions of this document may be illegible in electronic image products. Images are produced from the best available original document. 


\title{
Core, Edge, and Divertor LIDAR Thomson scattering for ITER *
}

\author{
A. W. Molvik, E. B. Hooper, R. A. Lerche, and M. D. Perry \\ LLNL, Livermore, California 94550 \\ $4 / 25 / 95$
}

We evaluated LIDAR Thomson scattering for application to the ITER core, edge, and divertor. Our designs differ in using a chirped pulse amplification laser ${ }^{1}$ of $\sim 10$ ps duration; a prism spectrometer which maintains a constant optical path length over its entire aperture, as required for high-spatial-resolution LIDAR (A filter spectrometer is satisfactory for the core); and a streak camera detector followed by a CCD camera.

We find that a $100 \mathrm{~Hz}, 10 \mathrm{ps}, 0.6 \mathrm{~J}$ laser would provide core resolution of $5 \mathrm{~cm}$ down to a density of $10^{18} \mathrm{~m}^{-3}$, edge resolution of $2 \mathrm{~mm}$ down to $2 \times 10^{19} \mathrm{~m}^{-3}$, and divertor resolution of $2 \mathrm{~mm}$ down to $10^{20} \mathrm{~m}^{-3}$. Higher energy, or reduced resolution are necessary to extend to lower densities. Each limit is for 600 detected photons, giving $\mathrm{n}_{\mathrm{e}}$ and $\mathrm{T}_{\mathrm{e}}$ to $10 \%$. The core and edge systems could be combined, using a beamsplitter with 2 streak cameras. An opportunity exists for a significantly improved divertor line-of-sight, by amending the system requirements to align the intercoil structure vanes with the SOL.

Two laser concepts, buildable today, are (1) $0.2-10 \mathrm{ps}$ pulse length at $800 \mathrm{~nm}, 0.6 \mathrm{~J}$, $100 \mathrm{~Hz}$ with a diode pumped final stage, costing $2.2 \mathrm{M} \$$ (1994); (2) If higher energy is needed, $2-20$ ps pulse length at $1053 \mathrm{~nm}, 6 \mathrm{~J}, 3-5 \mathrm{~Hz}$ flashlamp pumped, costing $1.5 \mathrm{M} \$$ (1994). The cost of diode pumping is dropping rapidly; higher energy, more rapidly pulsed lasers will be affordable within a few years. Either laser can be frequency doubled with an efficiency near $50 \%$. The $10 \mathrm{ps}$ laser beam needs to be transported with mirror optics, with the integrated window thickness kept below $1 \mathrm{~cm}$ to avoid beam breakup.

Prism dispersion is lower than that of a grating, but is adequate with lens coupling of the spectrometer to the streak camera with magnification.

The LLNL Laser Program Ultrafast Streak Camera provides time resolution of $10 \mathrm{ps.}$ Cylindrical electrostatic focusing of a $1.2 \mathrm{~mm}$ wide input slit produces an output resolution of $\sim 300 \mu \mathrm{m}$ corresponding to 120 pixels in time. ${ }^{2}$ An S-20 photocathode provides a high quantum efficiency at either 400 or $527 \mathrm{~nm}$.

Core and edge systems could be combined, beamsplitting to 2 -streak cameras. The systems could share a neutron maze, periscope system similar to that proposed for the core, by Salzmann, et al. ${ }^{3}$ For the core, slowing the streak camera sweep speed would yield a pixel limited spatial resolution of about $5 \mathrm{~cm}$ across the entire core, with $2 \mathrm{~mm}$ resolution available over the outer $24 \mathrm{~cm}$ regions. The edge location can be adjusted by varying the timing of the streak camera trigger. The core sensitivity is higher, so most of the light could be sent to the edge camera. Edge design features are listed below:

- The minimum density is $10^{20} \mathrm{~m}^{-3}$ at $5 \mathrm{~cm}$ resolution, and $\sim 2 \times 10^{19} \mathrm{~m}^{-3}$ at $2 \mathrm{~mm}$ resolution with a $0.3 \mathrm{~J}$, blue laser, $\mathrm{f} / 4.5$ final mirror, and viewing system transmission of 0.3 . Both $\mathrm{n}_{\mathrm{e}}$ and $\mathrm{T}_{\mathrm{e}}$ are determined to $10 \%$ with approximately 100 counts in each of 6 spectral channels. Lower densities could be measured either by slowing the streak camera for poorer spatial resolution or using a higher power laser.

- The laser is focused near the plasma edge to allow the laser beam to expand to a larger diameter and deliver a lower power density, below the wall ablation limit, on the inner wall. This also allows a smaller access hole in the neutron shield reducing neutron leakage if it isn't shared with the core system.

- The distance from the final focusing mirror to the focus is $\sim 3 \mathrm{~m}$, providing an $18 \mathrm{~ns}$ time difference between laser light backscattered from the final optic and the Thomson scattered signal from the plasma, sufficient time to gate the streak camera photocathode, deflection plates, and/or mcp intensifier to reduce scattered 
laser light from the final optics by 8 orders of magnitude to the order of the signal. This allows the viewing system to share optics with the laser. It has the advantage of $180^{\circ}$ backscatter, rather than near $180^{\circ}$ as on JET, providing complete overlap of the viewed region with the laser illuminated region.

In the divertor we propose to measure along the SOL from the strike point towards the X-point, rather than measuring across the width of the SOL which has a high probability of missing the most interesting region. This is the optimum line-of-sight, since the location of a gas target divertor ionization front along the SOL is unknown. 4 Some features and issues are:

- Intercoil structure vanes fill the region between toroidal field coils below the strike point.$^{5}$ By requiring that the vanes be aligned with the SOL above the strike point, a neutron maze similar to that proposed by Salzmann, et al., 3 can be used. The maze can be arranged with the optical path between vertical field coils.

- The hole diameter in strike plate needs to be large for a large signal and a long, non-vignetted view path, but needs to be small for minimum degradation of strike plate cooling. A compromise might be to use a small hole to pass the laser beam, surrounded by other small holes to view the beam. For an f/10 mirror, $3 \mathrm{~m}$ away, the holes would fill a $30 \mathrm{~cm}$ circle, and provide non-vignetted data to beyond the $X$-point. Care will be necessary to avoid blind spots.

- Laser power densities exceeding $\sim 10^{14} \mathrm{~W} / \mathrm{cm}^{2}$ near the focus will ionized gas; the resulting plasma density will be comparable to the divertor plasma for pressures near $10^{-2}$ Torr. This region could extend $0.6 \mathrm{~cm}$ either side of the focus with a $3 \mathrm{~J}$ laser. By locating the focus at least $2 \mathrm{~cm}$ below the strike point, the focus-plasma will provide a spatial fiducial, with a zero density region between the fiducial and the strike point to avoid perturbing the data.

Focusing a short pulse laser system within a plasma may be unsuitable for Thomson scattering because above some power density limit, non-linear effects will perturb the plasma electron density and axial velocity. This limit has not been determined experimentally. The conventional limit requires the oscillation velocity, vosc, of an electron in the laser field to be less than the electron thermal velocity, ${ }^{6}$ resulting in a power density limit of $4 \times 10^{15} \mathrm{~W} / \mathrm{cm}^{2}$ at $532 \mathrm{~nm}$ for $\mathrm{T}_{e}=100 \mathrm{eV}\left(\mathrm{P} / \mathrm{A} \propto \mathrm{T}_{\mathrm{e}} / \lambda^{2}\right)$. This limit is violated by orders of magnitude in recent laser gas-jet plasma experiments, 7,8 implying that the conventional limit is incorrect. Theory predicts that power densities of $3 \times 10^{17} \mathrm{~W} / \mathrm{cm}^{2}$ will perturb both the density and axial electron velocity. $9,10 \mathrm{We}$ are planning experiments on the Janus facility, that has a100 J, 0.1-1.0 ns, $1053 \mathrm{~nm}$ laser for ionizing and heating gas, and a $5 \mathrm{~J}, 1 \mathrm{ps}, 527 \mathrm{~nm}$ laser for probing the plasma. The experimental objectives are: to determine the laser power density limits for Thomson scattering, and to demonstrate proof-of-principle LIDAR Thomson scattering with a few millimeter resolution.

\section{References}

1. M. D. Perry and F. Mourou, "Terawatt to Petawatt Sub-ps Lasers,: Science 264, 917 (1994).

2. R. A. Lerche, et al., "Resolution limits and optimization of the LLNL streak camera focus," Proc. of SPIE Hi-Speed Photography, Vidiography \& Photonics V 832, 266 (1987).

3. H. Salzmann, et al., DRAFT: "Thomson Scattering in the Core, Edge and Divertor of ITER."

4. D. Post, et al., "ITER Divertor modeling: ...," IAEA-CN-60/E-P-7, Seville, (1994).

5. R. Bulmer, private communication, ITER Drawing 095039.

6. John Sheffield, "Plasma Scattering of E-M Radiation," Academic Press, NY, 1975, p. 20.

7. T. E. Glover, et al., Phys. Rev. Lett. 73, 78 (1994).

8. A. A. Offenberger, et al., Phys. Rev. Lett. 71, 3983 (1993).

9. W. L. Kruer, "Phys. of Laser Plasma Interactions," (Addsn-Wsly, Redwood City, CA, 1988).

10. C. B. Darrow, et al., Phys. Rev. Lett. 69, 442 (1992). 